\title{
Consideraciones éticas en la práctica médica
}

\section{Ethical considerations in medical practice}

\author{
Margarita Arancibia S. ${ }^{1,2,3}$
}

\begin{abstract}
Resumen
Actualmente la práctica clínica se ve enfrentada a una gran presión en los servicios clínicos públicos, privados, investigación, etc. El avance en ciencia y tecnología, asociado a gran publicidad por diversas redes, habitualmente no científicas, somete al cuerpo médico a una serie de dilemas éticos en forma diaria. Recursos limitados en el servicio público y una población que exige solución a sus problemas de salud, nos hace reflexionar sobre cómo tomar las decisiones más adecuadas, acudiendo a los principios éticos, cultivando valores personales, solicitando consentimiento informado, etc. Este texto pretende poner en contexto los temas de ética clínica con los que nos enfrentamos a diario.
\end{abstract}

Palabras clave: Ética, principios éticos.

\begin{abstract}
Clinical practice is currently facing a great pressure on the public and private clinical services, research, etc. The progress in science and technology, associated with great publicity through various networks, usually unscientific, subjects the medical staff to a number of ethical dilemmas on a daily basis. Limited resources in the public service and a population that demands solutions to its health problems, makes us reflect on how to make the most appropriate decisions, turning to ethical principles, cultivating personal values, requesting informed consent, etc. This text aims to put into context the clinical ethics issues that we face on a daily basis.
\end{abstract}

Keywords: Ethics, ethical principles.
'Servicio de

Otorrinolaringología, Hospital San Juan de Dios. Santiago,

Chile.

${ }^{2}$ Servicio de

Otorrinolaringología, Hospital Padre Hurtado. Santiago,

Chile.

${ }^{3}$ Departamento de Bioética, Facultad de Medicina, Universidad de Chile. Santiago, Chile.

La autora declara no tener conflictos de interés.

Recibido el 14 de julio de 2020. Aceptado el 4 de septiembre de 2020.

Correspondencia: Margarita Arancibia S. Pachica 8784, Las Condes. Santiago, Chile. Email: maggieara@gmail.com

\section{Introducción}

En la sociedad actual, moderna y diversa, los conceptos de ética y moral abarcan aspectos, políticos, sociales, económicos, salud, deporte, etc., pero muchas veces solo corresponden a un eslogan y no a una filosofía de vida, ya que las personas pueden tener diversas fuentes de guía moral. Sin embargo, en medicina los aspectos éticos tienen importancia relevante, en especial cuando nos enfrentamos a situaciones clínicas complejas que plantean un dilema ético, en este caso los médicos deben analizar, razonar y escuchar puntos de vista de otras personas involucradas en el caso y solicitar estudios y recursos especiales cuando sea necesario.

\section{Principios éticos}

El modelo principialista en bioética se relaciona con la publicación del libro "Principles of biomedical ethics" de Tom L. Beauchamp y James F. Childress en 2009, donde se presentan cuatro principios generales o cuatro conjuntos de principios, que serían valores morales, en torno a los cuales se agrupan los juicios y normas para la orientación ética de la práctica médica, tanto en la clínica como en la investigación ${ }^{1}$. Estos cuatro principios son: autonomía, beneficencia, no maleficencia y justicia. Cabe considerar que a estos principios se les ha hecho una jerarquización general, siendo la no maleficencia y justicia, principios de primer orden o públicos y principios de 
segundo orden o privado que corresponden a la autonomía y beneficencia.

Autonomía se refiere a que las decisiones tomadas por los pacientes deben ser en forma libre y soberana, teniendo información suficiente y sin presiones externas. El principio de beneficencia se refiere a que los médicos tienen el deber moral de actuar en el beneficio del paciente. Este debe fortalecer la confianza y tiene la obligación de actuar en el mejor interés del paciente, lo que debe prevalecer sobre los intereses del propio médico o el interés de terceras personas, como los hospitales o aseguradoras $^{2}$. Se debe evitar conductas paternalistas al intentar convencer de algún tratamiento, que el paciente no desea.

Un principio relacionado, no-maleficencia, es decir, "primero no lesionar" prohíbe al médico proporcionar tratamientos o intervenciones ineficaces o actuar sin el debido cuidado ${ }^{2}$. El principio de justicia proporciona una guía a los médicos sobre cómo tomar decisiones en la utilización y ubicación de recursos limitados e importantes, que debe ser equitativa y que incluye el propio tiempo ${ }^{3}$. Es importante actuar de manera consistente en casos que son similares en formas relevantes para la ética. De otra forma, las decisiones podrían ser arbitrarias, presentar sesgos y ser injustas. La justicia impide la discriminación en el sistema de salud en relación a grupo étnico, religión, género, orientación sexual u otra característica personal.

\section{Ética de la virtud y valores personales}

La ética de la virtud se centra en las características y cualidades del médico, se espera que este cultivará virtudes como la compasión, dedicación, altruismo, humildad e integridad ${ }^{2}$. Sin embargo, estas virtudes difícilmente se adquirirán o trabajarán a raíz de una profesión, estas son características que las personas que se dediquen a la salud, debieran haber desarrollado durante su vida, desde su infancia en su familia, escuela y universidad, y que no solo abarque la salud, si no la vida misma. Valores personales, tradiciones culturales y creencias religiosas son fuentes importantes de moralidad personal que ayudan a los médicos a atender problemas éticos en la práctica clínica.

\section{Respecto a la relación del médico con los pacientes}

El médico siempre debe tratar a los pacientes con respeto, esto implica comprender los objetivos del paciente con una comunicación eficiente, debe ser compasivo y dedicado y actuar en el mejor interés de estos y respetar su autonomía para tomar decisiones informadas con respecto a la atención médica² ${ }^{2}$

\section{Consentimiento informado}

Con el cambio de la medicina paternalista a la medicina que considera la autonomía como un principio fundamental y principal, se ha hecho necesario la implementación del consentimiento informado. Este es en realidad un proceso, mediante el cual el paciente ha recibido información acerca de su situación, su diagnóstico, las opciones terapéuticas, las consecuencias de cada una de ella para finalmente en forma consciente e informada tomar una decisión. Ocasionalmente, los pacientes podrían elegir no recibir tal información, pidiendo que un representante tome las decisiones en su nombre. En muchos casos este proceso se ha trasformado en un trámite burocrático con la mera firma de un papel para dar cumplimiento a una norma o ley (Ley 20584) ${ }^{4}$. Es importante tener claro que el paciente debe tener derecho a ser informado y consentir en las siguientes situaciones.

\section{En relación de su tratamiento}

Es necesario obtener el consentimiento informado y voluntario para intervenciones, respetar los rechazos del paciente cuando se haya brindado información y proteger la confidencialidad. El médico debe analizar con ellos en qué consiste la atención propuesta, las alternativas, los riesgos, los beneficios y probables consecuencias de cada opción y deben respetarse los valores y elecciones de los pacientes.

\section{En caso de urgencia}

Si los pacientes no pueden proporcionar su consentimiento en situaciones de urgencia y el retraso del tratamiento mientras espera a un 
representante pone en riesgo la vida y la salud del paciente, debe administrarse el tratamiento sin el consentimiento informado. Se presume que las personas desearían recibir la atención de urgencia a menos que con anterioridad hubieran indicado lo contrario.

\section{En caso de información delicada}

Cuando se deban informar malas noticias los médicos deben ser prudentes al entregar la información ofreciendo empatía y esperanza, proporcionar apoyo emocional y poniendo a su alcance otras ayudas como servicio social, cuidados paliativos y ayuda espiritual.

\section{En relación a imágenes, fotografías, videos o estudios imagenológicos}

Cuando el médico por razones científicas o para el control del mismo paciente, deba tomar imágenes de fotografías o videos, en cualquiera de las etapas del tratamiento, se debe explícitamente solicitar su consentimiento, para la difusión de estas imágenes o de estudios radiológicos, en reuniones científicas o publicaciones científicas.

\section{Evitar el engaño}

Bajo ninguna circunstancia el médico debe mentir u omitir información al paciente con el objetivo de beneficiarlo. El engaño, aunque sea por razones benéficas, es un problema ético y compromete la relación médico paciente.

\section{Confidencialidad}

En el juramento hipocrático, en la carta del profesionalismo médico, la ley de deberes y derechos de los pacientes y en nuestro código de ética del colegio médico, se ha preconizado el secreto profesional que consiste en conservar la confidencialidad de la información entregada por el paciente y que ha quedado registrada en la ficha clínica del paciente $e^{3-6}$. Esta confidencialidad puede ser superada cuando es necesario prevenir lesiones graves a terceras personas o al propio paciente. Las excepciones a la confidencialidad están justificadas si el riesgo es grave y probable, por ejemplo, violencia intrafamiliar, abuso sexual, enfermedades de transmisión sexual, etc.

\section{Pacientes que carecen de la capacidad de toma de decisiones}

En caso de incapacidad por inconsciencia, demencia, delirio u otras enfermedades, se debe ubicar al representante legal del paciente, habitualmente un familiar directo, aunque ocasionalmente el paciente previamente ha designado un representante. Las decisiones de los representantes deben guiarse por los valores, objetivos y preferencias expresadas previamente por el paciente. A veces también nos enfrentamos a que no hay familia que decida y entonces tenemos que tomar la decisión como equipo médico, autorizados por alguna autoridad legal. En este caso estamos enfrentados a las propias vicisitudes del deseo del médico y sus sentimientos ante el éxito o fracaso de su decisión 7 .

\section{Conflictos de interés}

Los conflictos de interés surgen cuando la relación médico-paciente se ve comprometida en el proceso de decisión por la aparición de otros intereses secundarios, como puede ser prestigio personal, prestigio académico, incentivos económicos ${ }^{8}$. Estos intereses pueden desviar la atención de lo que corresponde que es el mayor beneficio del paciente. Los médicos tienen la obligación de reconocer, y aclarar ante el público general, los conflictos de interés que surgen en el cumplimiento de sus deberes y actividades profesionales especialmente cuando determinan los criterios para conducir e informar ensayos clínicos, escribir editoriales, o guías terapéuticas, o actuar de editores de revistas científicas.

La receta médica debe tener una clara independencia e imparcialidad, libre de cualquier presión en su prescripción, como puede ser la industria farmacéutica9 ${ }^{9}$ Los médicos y la industria farmacéutica comparten el objetivo del progreso en el conocimiento científico; sin embargo, el principal interés del médico es proporcionar a sus pacientes el mejor tratamiento posible, mientras que el principal interés de la industria es vender su producto ${ }^{10}$. 


\section{Investigación científica}

La medicina ha avanzado durante el desarrollo de la humanidad por siglos y en los últimos periodos ha sido vertiginoso, esto ha permitido un estado de salud de la población mundial, en general con estándares muy buenos. Esto ha ocurrido gracias al conocimiento y la investigación científica y en este punto es importante recalcar que las investigaciones deben cumplir con los más altos estándares éticos, basados en pautas internacionales, como la declaración de Helsinki (con sus reformas) ${ }^{11}$ y como lo señala la declaración del profesionalismo médico ${ }^{3}$ en 1999 , la profesión médica tiene un compromiso en el desarrollo del conocimiento científico, promoviendo la investigación, creando nuevos conocimientos y asegurando su adecuada utilización. En este mismo sentido, los médicos deben tener un compromiso con la docencia, tanto entre colegas como en las disciplinas afines.

\section{Epílogo}

La motivación a escribir este artículo, nace por la necesidad de comunicar a los médicos de la especialidad, algunos conceptos de bioética, probablemente muy conocidos por algunos, pero probablemente no tanto para otro grupo. Especialmente por la situación actual, dada por una pandemia mundial, nos veremos enfrentados a situaciones muy difíciles, por un periodo largo de tiempo, donde tendremos conflictos en todos los puntos establecidos en este texto.

\section{Bibliografía}

1. Beauchamp TL, Childress JF. Principles of biomedical ethics. $6^{\text {a }}$ ed. New York: Oxford University Press, 2009.

2. Bernard L, Christine G. Aspectos éticos en la medicina clínica. Harrison. Principios de Medicina Interna, 19 ed., cap. 17.

3. Profesionalismo médico en el nuevo milenio: una declaración para el ejercicio de la medicina. Declaración conjunta de la Federación Europea de Medicina Interna, American College of Physicians American Society of Internal Medicine (ACP-ASIM), American Board of Internal Medicine. Ann Intern Med. 2002; 136:243-6.

4. Ley 20584, Biblioteca del Congreso Nacional de Chile. https://www.minsal.cl/sites/default/files/files/Ley\%20 20584\%20Derechos\%20y\%20Deberes.pdf

5. Juramento Hipocrático, Código de Ética Colegio Médico.

6. Código de Ética, Colegio Médico, Titulo III, Cap.3.

7. Arancibia M. Pensamientos sobre como enfrentar el sufrimiento en personas mentalmente discapacitadas y que padecen una enfermedad grave. Rev Otorrinolaringol Cir Cabeza Cuello. 2007;67(2):149152.

8. Ortiz-Pommier A. Conflicto de intereses en la relación clínica. Revista chilena de neuropsiquiatría. 2004; 42(1):29-36. doi: 10.4067/S071792272004000100004

9. Santa Cruz P. La industria farmacéutica y su influencia en la práctica clínica. Rev GPU. 2011; 7(1):92-102.

10. Peralta V. Ensayos clínicos, industria farmacéutica y práctica clínica. Anales del Sistema Sanitario de Navarra. 2005; 28(1):7-16.

11. Manzini JL. Declaración de Helsinki: Principios éticos para la investigación médica sobre sujetos humanos. Acta Bioethica. 2000; 6(2):321-334. 